\title{
Discutindo estratégias para a construção de questionários como ferramenta de pesquisa
}

Waisenhowerk Vieira de Melo

Cristina dos Santos Bianchi

\section{Resumo}

O questionário de pesquisa é uma das ferramentas mais utilizadas por pesquisadores em Ciências Sociais. Por isso, a elaboração das perguntas é etapa crucial para a obtenção de um bom questionário, isto é, de um questionário que cumpra seu papel na coleta de dados de maneira a revelar, da melhor forma possível, a realidade dos fatos ocorridos dentro do alvo do estudo proposto. Neste artigo, tecemos algumas considerações, através de esquemas e exemplos, para a formulação de um questionário de pesquisa profícuo. A nossa experiência com alunos da graduação em Biologia e da pós-graduação em ensino de Ciências de UERJ nos fornece as informações sobre os erros mais comuns, e a base para a adoção dos procedimentos mais adequados na colaboração para minimizar tais erros, e facilitar a construção de questionários de pesquisa.

Palavras-chave: questionário de pesquisa; metodologia; pesquisa em ensino de Ciências e Biologia.

\section{Abstract \\ Discussing strategies for the construction of questionnaires as powerful research tools}

The questionnaire is one of the most used tools by investigators in Social Sciences. Therefore, the preparation of the questions is a crucial stage for making a good questionnaire, that to fulfill its objective in collecting data in order to show, in the best possible way, the accuracy of facts occurred whilst this research study was being carried out. In this article, we weave some considerations, by using schemes and examples, for the formulation of what we consider to be a fruitful questionnaire. Our experience with students both from the Biology graduation course as well as from the post-graduation course in Teaching of Science, offered at Universidade do Estado do Rio de Janeiro (UERJ) supplies information on common mistakes made and points out possible proceedings in order to minimize them, offering valuable insights on the construction process of this kind of questionnaires.

Keywords: questionnaire; methodology; investigation in Teaching of Science and Biology. 


\section{Introdução}

A nossa experiência empírica na correção e na elaboração de questionários de pesquisa nos mostrou a necessidade de produzir este artigo, que visa trazer à baila para discussão alguns pontos que julgamos fundamentais na elaboração de um bom questionário, entendido como um instrumento de coleta profícuo, quer dizer, que traga para a pesquisa - em nosso caso, a pesquisa em Ensino, de caráter predominantemente qualitativo (LUDKE e ANDRÉ, 1986; NEVES, 1996) - as respostas que satisfarão os questionamentos por ela suscitados.

A dificuldade encontrada por alunos da graduação em Licenciatura em Biologia e da pósgraduação em Ensino de Ciências da UERJ, sob a nossa orientação, nos fornece dados para a realização deste estudo. A área da Biologia, entretanto, não limita o aproveitamento destas recomendações, uma vez que os trabalhos têm como temática a Educação, objeto de estudo da Sociologia, que por sua vez, faz parte do currículo das Ciências Sociais.

A grande demanda atual por cursos de pós-graduação na área de ensino de Ciências no Brasil produz uma população de alunos maior e mais heterogênea, com pouca experiência de contato com a pesquisa (GURIDI et al., 2005). É comum encontrarmos estudantes inexperientes na pesquisa em Educação, que não tomam o devido cuidado na elaboração de um questionário para sua pesquisa, por considerarem fácil sua execução ou não o contextualizarem dentro do seu estudo.

Assim, professores recém-formados, sobretudo os que não tiveram a oportunidade de cursar uma pós-graduação, também irão encontrar dificuldades na condução de pesquisas em Educação. Moreira (1988) conclama os professores a se engajarem na pesquisa em Ensino, já que são internos ao seu ambiente, que é a sala de aula. Provavelmente, estes serão pesquisadores inexperientes, com dificuldades nas etapas do processo de pesquisa, inclusive na elaboração de um bom questionário.

Por isso, ressaltamos também a importância da observação da construção de todos os passos da pesquisa, que segundo Gil (2009), e adaptado por nós, incluem:

- Formular o problema

- Buscar diálogo com a literatura pertinente

- Determinar os objetivos/construir hipóteses

- Produzir um desenho experimental/delineamento da pesquisa

- Operacionalizar conceitos e variáveis

- Selecionar a amostra a ser pesquisada

- Elaborar os instrumentos de coleta de dados

- Analisar e interpretar os resultados

- Produzir a escrita (relatório, artigo, monografia etc.) 
A diligência na contextualização e construção dos instrumentos de coleta de dados é crucial para a validação da pesquisa, uma vez que faz parte de toda uma estrutura que lhe dá origem.

Um questionário, segundo Gil (2009), é uma técnica de investigação com questões que possuem o propósito de obter informações; segundo Parasuraman (1991), é um conjunto de questões feito com o fim de gerar os dados necessários para se atingirem os objetivos de um projeto, sendo muito importante na pesquisa científica, especialmente nas Ciências Sociais. Embora não exista uma metodologia padrão, o questionário precisa ser formulado de modo a atender ao objetivo do trabalho.

Reforçamos que o questionário não deve ser confundido com a metodologia da pesquisa realizada, pois é apenas ferramenta para colher dados dentro do estudo. E como tal, sua função não é diminuída, ao contrário, passa a ser o motor que propulsiona o andamento do estudo. Algumas pesquisas só podem ser realizadas através de questionários como meio de coleta de dados. Tomemos como metáfora um termômetro clínico (ferramenta); a aferição da temperatura de uma pessoa é apenas um dado para o diagnóstico, que será formulado pelo especialista e, dentro de um contexto.

E apesar de um questionário ser muito importante dentro de estudos de temas das Ciências Sociais, é preciso prestar atenção ao tipo de pesquisa realizado e à viabilização da aplicação das questões, tomando como referencial a reflexão proposta: a única forma de obter dados para esta pesquisa é através de questionários, ou existem outras formas de obtenção que complementem ou substituam o questionário, como por exemplo, entrevistas dentro da pesquisa proposta ou mesmo análises documentais?

A utilização indevida de um questionário, ou um questionário mal formulado, pode resultar na geração de informações equivocadas e causar erros de conclusões, afetando a validade do estudo. Isso reforça a necessidade de refletir sobre todos os aspectos da pesquisa antes de se valer de um questionário para fazer a coleta de dados.

Durante a elaboração do questionário é recomendável que uma pessoa experiente no assunto faça uma avaliação e conseguinte aprovação, antes de passar à etapa da validação interna - entendida como a verificação de se o questionário mede o que está proposto a aferir (HOSS; CATEN, 2010). Na validação interna ${ }^{1}$, o questionário é testado em uma pequena amostra do público-alvo. Todo questionário precisa passar por esta averiguação, pois esta etapa ainda faz parte da sua construção, objetivando adequar sua linguagem e depurar seu conteúdo. A finalização de um questionário de pesquisa, portanto, só pode ser dada após vários testes na sua construção.

\footnotetext{
${ }^{1}$ Não iremos nos aprofundar nas mensurações quantitativas de validação interna, já que nossa proposta de análise é fundamentalmente qualitativa.
}

R. B. E. C. T., vol 8, núm. 3, mai-ago.2015 ISSN - 1982-873X

DOI: Em andamento. 
Neste artigo, pretendemos indicar, através de sugestões e exemplos, caminhos para a construção de um bom questionário de pesquisa, isto é, um questionário que cumpra sua função, como coletor de dados de maneira clara e precisa, minimizando a margem de erros da interpretação das respostas. Isto o transforma em uma ferramenta mais segura e profícua.

\section{Problemas mais comuns encontrados nos questionários}

Para proceder a esta análise, selecionamos questionários construídos por alunos da graduação e pós-graduação que chegaram a nós para orientação no último ano de 2013. Destes, e dos autores que embasam esta questão (CHAGAS, 2000; GÜNTER, 2003), construímos e generalizamos os exemplos de erros mais comuns.

Analisemos alguns problemas gerais destes questionários:

- Perguntas que se autorrespondem.

Exemplo: "Os alunos preferem aulas práticas?" Esta pergunta até pode ser considerada uma afirmação, dada a obviedade de seu conteúdo.

- Perguntas que induzem a resposta.

Exemplo: "Você tem bons hábitos de higiene?" Os predicativos positivos são preferidos dentro de uma população, tornando esta pergunta, condicionante da resposta.

- Perguntas que não trazem a informação pretendida.

Exemplo: "Você trabalha em algum emprego?", quando a intenção era saber se a pessoa possui alguma fonte de renda.

- Questionários muito longos.

Um questionário muito longo pode ser cansativo e gerar respostas não condizentes com a realidade. Ao se cansarem as pessoas respondem de qualquer maneira, ou simplesmente não respondem às questões. No entanto, pode haver eventos em que haja necessidade de que o questionário seja longo para a obtenção da resposta. Neste caso, deve-se formulá-lo da maneira mais agradável possível.

- Questionários muito curtos.

Questionários curtos demais representam um risco de investimento com baixo retorno. Um questionário destes pode não conter as perguntas necessárias para responder ao objetivo da pesquisa. Atenção, isso não significa que um bom questionário não possa ser curto.

- Questionários sem coordenação lógica.

A ordem das questões deve obedecer a uma lógica. As perguntas devem ser agrupadas por assunto e enumeradas de forma a facilitar sua localização. 
- Questionários sem preocupação com a estética.

O tamanho da fonte, da folha e a estética do questionário contribuem para a colaboração dos participantes. Alguns questionários são feitos com pouco espaço para respostas ou são distribuídos em folhas pequenas, com fonte de letra menor que o aconselhável para o público estudado. Pessoas com idade avançada, por exemplo, possuem dificuldades visuais que uma fonte de tamanho maior pode minimizar. Seguir padrões visuais ajuda a construção de uma estética agradável, o que contribui para a colaboração dos participantes.

- Falta de preocupação com o tamanho da amostra.

Quando pretendemos aplicar um questionário precisamos avaliar se o tamanho da amostra necessita de um questionário. Populações-alvo muito pequenas, como 10 participantes, por exemplo, permitem o uso de entrevistas. Não queremos dizer, portanto, que a substituição seja obrigatória, mas deve ser considerada.

\section{Preocupações ao formular um questionário}

Insistimos nas recomendações técnicas, que traduzem reflexões importantes para a pesquisa. Chagas (2000) e Günter (2003) continuam a nos auxiliar nas recomendações, pois quando pretendemos iniciar a formulação de um questionário de pesquisa, precisamos ter em mente algumas preocupações relevantes:

- $\mathrm{O}$ que se quer saber?

O que queremos saber torna-se o eixo condutor da construção do questionário e pode ser traduzido como o problema da pesquisa. A partir do problema e do levantamento das hipóteses podemos traçar o objetivo do estudo. Um objetivo bem delimitado torna mais fácil a formulação de questões mais claras. É necessário, portanto, verificar se os dados que o questionário vai trazer são pertinentes ao tema da pesquisa, considerando que o questionário é apenas ferramenta de coleta de dados.

- Qual o público-alvo?

A consideração de qual público-alvo participará do estudo é de suma importância na construção de um questionário de pesquisa, haja vista pretendermos obter respostas que traduzam a realidade do respondedor. Idade, condição socioeconômica, padrões culturais, região geográfica e nível de escolaridade, por exemplo, devem ser analisados para adaptação da linguagem, assim como seleção de padrões estéticos do questionário.

- Padrões de estética.

Precisamos prestar atenção ao elaborarmos o texto do questionário para que sua visualização se torne fácil e agradável. Questões econômicas podem nos levar a diminuir o

DOI: Em andamento. 
tamanho da fonte utilizada ou o tamanho do papel, por exemplo, mas isto é desaconselhável, pois pode influenciar negativamente na obtenção das respostas. Adotar um padrão de estética pode, inclusive, facilitar a elaboração das questões e da sequência lógica a ser seguida.

- Produção de questões que não sejam dúbias.

Devemos nos preocupar em produzir questões isentas de ambiguidade. Ao formularmos as perguntas, devemos procurar torná-las compreensíveis a qualquer leitor. Precisamos nos lembrar de que cada indivíduo possui uma interpretação de textos peculiar e que o questionário nem sempre será explicado pelo autor das questões. A etapa de validação interna é fundamental neste caso, já que só conseguimos ter uma ideia da compreensão dos respondentes a partir do momento que analisamos suas respostas. E ressaltamos que neste item, encontramos muita resistência dos iniciantes na pesquisa, ao suporem que uma vez elaborado, o questionário já está concluído e pronto para ser distribuído ao seu público-alvo.

\section{Conteúdos das perguntas}

A seleção das perguntas que são realmente necessárias é fundamental. Algumas questões podem se tornar repetitivas ou sem objetivo. A clareza de vocabulário é o principal requisito para explicitar o conteúdo da questão, facilitando assim, sua seleção ou modificação se for necessário. Por outro lado, não devemos economizar perguntas para tratar de assuntos complexos, evitando abordar mais de um assunto em uma única questão.

Devemos evitar os seguintes tipos de perguntas: que sugiram ou condicionem a resposta, que possuam conteúdo emocional, que levem o respondente à necessidade de fazer cálculos, que façam alusão a nomes que impliquem em aceitação ou rejeição e que contagiem outras respostas. Alternativas muito longas dificultam a compreensão das ideias contidas e também devem ser evitadas (CHAGAS, 2000).

Outras recomendações mais específicas no tocante ao vocabulário, como evitar o uso de palavras ambíguas, complicadas ou distantes do quotidiano do público-alvo também são de grande valia.

\section{Sequência lógica das perguntas}

As perguntas devem ser posicionadas dentro do questionário obedecendo a uma sequência lógica (GÜNTER, 2003). A primeira recomendação é que as perguntas estabeleçam uma continuidade, uma ligação entre si, evitando mudanças repentinas de temas. Segundo Mattar (1994), a primeira pergunta deve ter como objetivo deixar o respondente à vontade para prosseguir no questionário, para isso, iniciando com uma pergunta aberta, ou seja, onde o respondente possa expressar sua opinião. Fazemos nossas as recomendações do autor, sobre 
iniciar o questionário com perguntas gerais independente de serem abertas, e deixar perguntas pessoais ou específicas para o final, a não ser que tenham que servir como filtro.

\section{Análise de um questionário formulado por estudante/pesquisador inexperiente}

A análise qualitativa (LUDKE e ANDRÉ, 1986; NEVES, 1996) de um questionário formulado sem uma orientação prévia nos dará a noção de alguns erros que devemos evitar. Apresentamos um questionário formulado por uma professora de Ciências no início de 2008, que tinha como objetivo colher dados para escrever um projeto de pesquisa, visando pleitear uma vaga em um concurso para ingresso no Mestrado. Sua intenção era pesquisar o porquê de professores da educação básica na área de ciências naturais não realizarem aulas práticas.

Adiantamos que ao construir este questionário, a professora já tinha como objetivo confirmar suas certezas de que professores não realizam aulas práticas, e não, levantar dados para uma análise, deflagrando seu primeiro erro. Isto pode ser considerado um dos erros mais graves na construção de um questionário, pois é erro de estruturação da pesquisa.

A professora demonstrou deficiência na sua formação para a realização de pesquisas, haja vista que por mais que saibamos que todo o conhecimento seja afetado pela predisposição dos observadores (GIL, 2009), é necessário fruir da contribuição do método científico na pesquisa qualitativa, que se funda em ser norteador do rigor dos procedimentos e da imparcialidade do pesquisador. Com sua "hipótese", ela influenciou a construção do questionário, tornando-o tendencioso. Segundo Moreira (1988, p.52): “O que caracteriza a atividade de pesquisa é a observação controlada, a conversão de eventos em registros e estes, através de transformações metodológicas, em asserções de conhecimento."

Eis o exemplo, onde as questões da professora estão em negrito, em seguida, nossos comentários:

Caro (a) professor (a), este questionário faz parte de uma pesquisa pessoal com objetivo de colher dados para estudo. Não há necessidade de identificação, mas sua contribuição é muito importante. Agradeço desde já a boa vontade em participar deste trabalho.

As informações do cabeçalho não devem mostrar interesse apenas pessoal, mas de alguma forma, que irá contribuir para a produção de um conhecimento que gere retorno coletivo (GÜNTER, 2003); de outra forma, poderá dar a impressão de que a pesquisa trará vantagens pessoais.

1) Que disciplina você leciona?

$($ ) Química (EM) ( Física (EM) $\quad(\quad$ ) Biologia (EM)
$($ ) Ciências (EF)

R. B. E. C. T., vol 8, núm. 3, mai-ago.2015 ISSN - 1982-873X

DOI: Em andamento. 
A disposição das opções deve obedecer a um padrão estético; ou lado a lado ou uma abaixo da outra. Observamos nesta pergunta que as opções para resposta estão desalinhadas. Deve-se também, evitar o uso de abreviaturas ou identificá-las no corpo do questionário. Exemplo: EM= Ensino Médio e EF= Ensino Fundamental.

\section{2) Há quanto tempo leciona?}

( ) Há menos de 3 anos ( ) Entre 3 e 10 anos

( ) Há mais de 10 anos

Estes intervalos de tempo foram estabelecidos sem nenhuma referência que os justifique.

3) Você costuma dar aulas práticas (em laboratório, em sala de aula ou outro espaço)? ( ) Sim ( ) Não

A pergunta é passível de interpretações do que seja uma aula prática. O professor pode considerar, por exemplo, uma pequena demonstração, como jogar um objeto para o alto, uma aula prática.

4) Se a resposta anterior foi Não, indique o(s) motivo(s) que o impede de realizá-las: (Se foi Sim, ir direto à no 5).

( ) Não gosto deste tipo de aula ou não acho proveitoso para o aprendizado.

Esta alternativa mostra duas opções em um único item: "Não gosto deste tipo de aula." e "Não acho este tipo de aula proveitoso para o aprendizado.". Além disso, questões que revelem pontos negativos são consideradas invasivas, e devem ser deixadas para o fim do questionário, conforme indicaremos ainda nesta proposta.

( ) Acho importante mas não tenho tempo de prepará-las; trabalho muito.

Esta alternativa possui uma justificativa, limitando-a. A falta de tempo pode não estar condicionada a trabalhar muito. Envolve também a interpretação de "trabalho" como qualquer atividade não remunerada, como no caso da dupla jornada de trabalho feminino, o que pode estar excluído nesta alternativa.

( ) A escola onde trabalho não tem Laboratório.

( ) $O$ Laboratório da escola onde trabalho não tem infraestrutura (espaço, material, etc.) para levar os alunos.

( ) Minhas turmas têm um número de alunos maior que o adequado (mais que 35) e é difícil manter a disciplina.

( ) É perigoso ou faz muita sujeira aula prática com os alunos.

Encontramos novamente, nas duas alternativas anteriores, duas opções na mesma frase. 
( ) Acho que ganho muito pouco para ter tanto desgaste.

( ) Não me acho preparado o suficiente ou não saberia preparar uma aula prática; precisaria fazer cursos, me atualizar.

( ) Já dei aulas práticas, mas hoje em dia os alunos estão cada vez mais desinteressados, então fico desanimado.

( ) A direção da escola não apoia aulas práticas ou não tenho estímulo da direção ou dos colegas professores.

Nesta alternativa existem três opções: "A direção da escola não apoia aulas práticas", "Não tenho estímulo da direção" e "Não tenho estímulo dos colegas". A alternativa não fornecerá uma informação precisa.

( ) Outros motivos. Quais?

Note que esta questão número 4 possui 10 opções, e ainda assim não esgotou as possibilidades de resposta. $O$ ideal é que ela seja uma pergunta aberta.

5) Se a resposta no 2 foi Sim, responda:

a) Com que frequência você dá aulas práticas?

( ) 1 vez ao ano ( ) 2 vezes ao ano ( ) entre 4 e 8 vezes ao ano

( ) mais de 8 vezes ao ano

Por que a opção "3 vezes ao ano" não fez parte das alternativas? Observe o mesmo erro estrutural da questão 2 . Note também a falta de padrão estético.

b) Quanto ao desempenho do aluno:

( ) É melhor nas aulas práticas que nas teóricas.

( ) É o mesmo que nas aulas teóricas.

( ) A maioria não se interessa tanto pela prática.

Esta pergunta pode não refletir uma realidade vivida pelo professor, e sim, sua opinião. Tornou-se, portanto, uma pergunta condicionante da resposta.

Em uma análise geral, podemos dizer que este questionário foi elaborado açodadamente, sem técnica e buscando antes, demonstrar certezas do que cotejar dados para uma pesquisa.

\section{Discussão de nossa análise}

Da análise do questionário construído pela professora de Ciências levantamos alguns pontos relevantes. Primeiramente, destacamos que se constitui em um exemplo extremo de um

DOI: Em andamento. 
questionário mal formulado, resultado de sua falta de experiência com a pesquisa e de ter sido construído sem qualquer orientação prévia. Por isto mesmo o utilizamos, por conter a maioria dos exemplos que desejávamos explorar, sem, no entanto, generalizarmos insinuações sobre o nível de conhecimento dos principiantes na pesquisa em Ensino.

Seu erro de estruturação da pesquisa demonstra a lacuna da formação de professores de ciências, como de outras disciplinas no Brasil. "Diferente de outras atividades acadêmicas, pesquisar exige um envolvimento que requer assumir uma posição de 'autoria' e não da mera reprodução de conhecimentos" (ROSA, 2010, p. 605). Ainda vivemos um cenário onde se acredita que um ensino de qualidade depende basicamente do domínio de técnicas metodológicas de ensino, e assim temos cursos de Licenciatura que corroboram a reprodução de professores proletariados (APPLE, 1987), com dificuldades de refletir sobre sua prática, menos ainda, de transformar seu trabalho em uma produção intelectual (GIROUX, 1997).

Dentro desta perspectiva, sentimos a necessidade de simular um "passo a passo" com etapas básicas e com o auxílio de um organizador mental e estrutural, o roteiro de questionário (ver próxima seção: "Recomendações para a construção de um bom questionário"), para que através destes, tanto o processo de construção do questionário quanto o embasamento para a sua formulação sejam continuamente revisitados, de forma a potencializar os resultados, beneficiando toda a pesquisa. Cremos que as minudências de nossas sugestões sejam deveras oportunas, refletindo nossa preocupação com a formação de pesquisadores autônomos e responsáveis, e nosso comprometimento com o rigor do método científico.

É preciso que esclareçamos nosso posicionamento sobre o método científico em relação à pesquisa qualitativa, já que nos valemos do termo e este tema tem sido alvo de discussões (GÜNTER, 2006; TURATO, 2005). Para contextualizar a questão, é necessário que entendamos a ciência como um constructo histórico-cultural, e que seu método entendido como empiristaracionalista, tem sido valorizado desde o século XVII. Disto resulta, a partir do século XIX, uma tentativa de aproximação deste modelo de racionalidade às ciências sociais emergentes, e o surgimento de uma categoria de conhecimento "intruso e desqualificado", os estudos humanísticos (SANTOS, 2010).

Contudo, um novo paradigma estruturado no questionamento da superioridade racionalista e da exclusividade de seus métodos quantitativos para as ciências sociais, vem à tona. Nosso lugar de pesquisadores em Ensino cabe a consciência do valor social de nossos estudos e o rigor do método científico na estruturação dos passos a serem seguidos e na análise de resultados, sem as imposições quantitativas do método na pesquisa social. Partimos da compreensão de que em uma pesquisa qualitativa, são necessárias por vezes, abordagens quantitativas, como pode ser o caso de muitas formas de avaliar os de dados de um questionário. A questão não é decidir entre uma abordagem e outra, mas qual(is) abordagem(ns) é(são) 
melhor(es) para responder às questões do problema de pesquisa (GÜNTER, 2006), ficando evidente que são complementares.

Outro ponto que iremos ressaltar é o questionamento inicial proposto em nossa Introdução: "a única forma de obter dados para esta pesquisa é através de questionários, ou existem outras formas de obtenção de dados que complementem ou substituam o questionário, como por exemplo, entrevistas dentro da pesquisa proposta ou mesmo análises documentais?" No caso da pesquisa proposta pela professora, um acervo bibliográfico com a questão já estava disponível à época em que elaborou o questionário, e poderia ter sido sua diretriz principal, evitando formular questões já bastante respondidas na literatura. Reforçamos que seu erro de estruturação de pesquisa, considerado o mais grave, dá-se pela falta de atenção ao passo fulcral na sua constituição, que é, voltando à nossa Introdução, "Buscar diálogo com a literatura pertinente".

\section{Recomendações para a construção um bom questionário}

Tecemos aqui nossas considerações, com esquemas que projetamos para auxílio na construção de um questionário profícuo, divididas em quatro etapas.

Primeira etapa: Montagem de um "roteiro de questionário" (RQ). O RQ é um protocolo ou formulário onde as perguntas são criadas sob a forma de rascunho, e passam por uma seleção. Todo processo de pesquisa deve ser documentado, por isso, indicamos na figura 1, um modelo de RQ que viabilize este fim.

\begin{tabular}{|c|c|}
\hline $\begin{array}{l}\text { Instituicäo: } \\
\text { Nome: } \\
\text { Objetivo da pesquisa: }\end{array}$ & $\begin{array}{l}\text { Departamento / Disciplina: } \\
\text { Titulo do projeto: } \\
\text { Data: }\end{array}$ \\
\hline O que eu quero saber & Perguntas que trar ّ̋o a resposta \\
\hline & \\
\hline & \\
\hline
\end{tabular}

Figura 1: Modelo de formulário (RQ)

(Fonte: autores)

No RQ deve constar o cabeçalho, que identifica a instituição, departamento, curso, disciplina, nome dos pesquisadores, data, título do projeto e objetivo da pesquisa. Longe de transformá-lo em procedimento burocrático, o objetivo do cabeçalho é registrar o processo de pesquisa, uma vez que toda atividade científica deve ser plenamente documentada. Como documento interno, pode ser abreviado, porém deve explicitar o objetivo da pesquisa, o que norteará a criação das perguntas.

DOI: Em andamento. 
Dividimos o roteiro em duas colunas, a saber: na primeira coluna consta o título "o que eu quero saber", que se resume no objetivo do questionário. Nesta, são escritas as perguntasproblema para a elaboração das questões que poderão levar o pesquisador a obter a resposta, a serem escritas na segunda coluna intitulada "perguntas que trarão a resposta".

\section{Procedimentos para preenchimento do RQ}

Demonstramos um esquema na figura 2 que pode servir como exemplo de rascunho para a formulação de questões no RQ. Enumeramos na primeira coluna o que queremos descobrir e, na segunda coluna, utilizamos o método conhecido como tempestade cerebral - "brainstorm" - para a criação de várias questões pertinentes a cada pergunta-problema formulada na coluna intitulada: "o que eu quero saber".

Observe ainda na figura 2, que a pergunta-problema está inserida em uma hipótese que será testada. Após o "brainstorm", as questões formuladas serão analisadas e poderão ser reformuladas.

\begin{tabular}{|c|c|}
\hline $\begin{array}{l}\text { Instituicão: } \\
\text { Nome: } \\
\text { Objetivo da pesquisa: }\end{array}$ & $\begin{array}{l}\text { Depatamento/ Disciplina: } \\
\text { Titulo do projeto: } \\
\text { Data: }\end{array}$ \\
\hline $\begin{array}{c}\text { O que eu quero saber } \\
\text { (objetivo do questionário) }\end{array}$ & Perguntas que traräo a resposta \\
\hline $\begin{array}{c}\text { Pergunta problema: } \\
\downarrow \\
\text { Hipótese: }\end{array}$ & $\begin{array}{c}\text { Formulagäo de vírias questóes } \\
\text { (tempestade cerebral) } \\
\mid\end{array}$ \\
\hline $\begin{array}{c}\text { Análise das questöes formuladas } \\
\begin{array}{c}\downarrow \\
\text { Reformulagão de questöes (se } \\
\text { necessário) }\end{array}\end{array}$ & $\begin{array}{l}\text { Questöes formuladas } \\
\text { Questöes refomuladas }\end{array}$ \\
\hline
\end{tabular}

Figura 2: Exemplo de como preencher o $R Q$

(Fonte: autores)

A partir deste modelo proposto, exemplificaremos a construção de perguntas de um questionário, ilustrado na figura 3.

Imaginemos primeiramente, a situação de um docente que está preocupado com a disciplina na rotina de estudos de seus alunos do Ensino Fundamental. Sua hipótese é a de que a maioria dos alunos não estuda em casa por iniciativa própria, e assim, inicia sua pesquisa. 


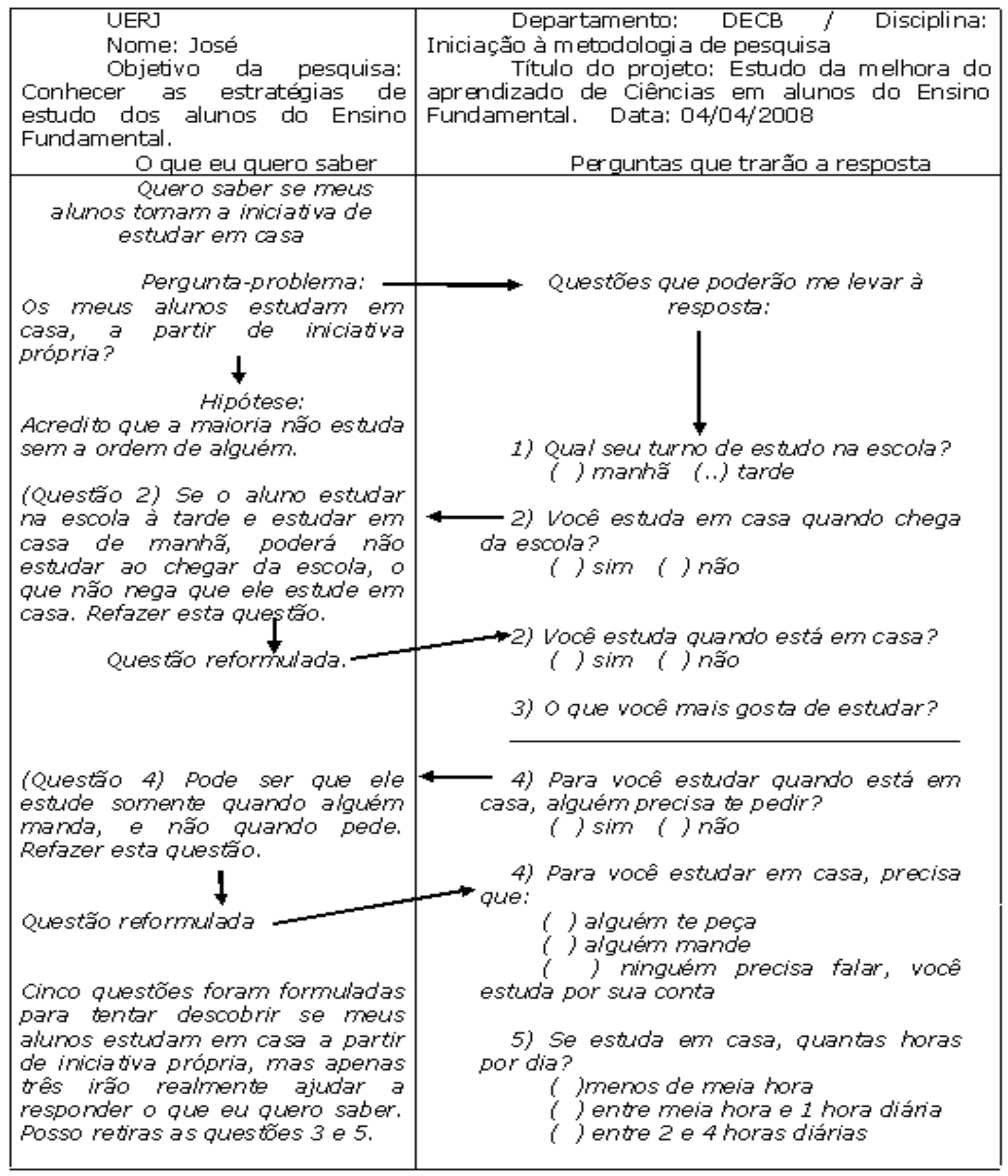

Figura 3: Rascunho de formulação de perguntas em um $R Q$

(Fonte: autores)

Delimita, então, um objetivo de pesquisa claro: “Conhecer as estratégias de estudo dos alunos do Ensino Fundamental", traduzida em "o que eu quero saber", através da questão "Quero saber se meus alunos tomam a iniciativa de estudar em casa”. Após, procede à formulação da pergunta-problema: “Os meus alunos estudam em casa, a partir de iniciativa própria?”

Para fazer tal verificação, são construídas várias questões para conseguir a informação. Estas devem ser analisadas cautelosamente e reformuladas, se necessário. Veja que no exemplo

DOI: Em andamento. 
da ilustração, a questão número dois estava muito específica para estudantes do turno da manhã, sendo reformulada para poder ser aplicado a outro turno. Já a questão número quatro, continha um enunciado específico que poderia ser interpretado erroneamente.

Note que cinco questões foram formuladas, mas somente três delas trazem a informação desejada, ficando a critério do pesquisador, retirá-las. O ponto positivo de mantê-las é a possibilidade de criar mais interesse de responder o questionário, beneficiando a pesquisa (GÜNTER, 2003).

Construído o questionário, distancie-se dele por alguns dias. Isto proporcionará outro olhar às questões elaboradas com possíveis reformulações, ou mesmo triagens. Com os resultados, poderemos confirmar ou não a hipótese levantada. Porém, devemos lembrar que a análise do resultado do questionário é apenas parte do estudo proposto.

Segunda etapa: Confecção física do questionário com as perguntas selecionadas, levando em conta o que já foi discutido sobre estética.

Terceira etapa: Avaliação do questionário junto com os pares pertencentes à pesquisa. A visão do questionário por uma pessoa que não foi envolvida da construção do questionário é fundamental, pois propicia um novo olhar, não imerso nesta etapa do projeto de pesquisa.

Quarta etapa: Validação interna através da execução de um pré-teste em uma pequena amostra da população-alvo, com análise de possíveis erros. Nenhuma quantidade de pensamento pode substituir a verificação empírica (GOODE e HATT, 1972).

\section{Considerações finais}

O "ajuste" de ferramentas de pesquisa, em particular o questionário, é primordial para a realização de um projeto. Um termômetro clínico mal calibrado, voltando à metáfora inicial, fornece informações inúteis para formar um diagnóstico sobre o estado de um indivíduo.

A elaboração de um bom questionário como ferramenta de pesquisa, no entanto, não é tarefa fácil. É preciso cautela e atenção para esta etapa que é fundamental na pesquisa. Um trabalho feito sem preocupação pode conduzir a análises precipitadas levando a conclusões sem ter havido de fato uma averiguação dos dados, portanto, inválidas. Esta questão já é discutida desde 1950 por Selltiz, Wrightsman e Cook (1987), onde, introduzindo o método científico nas ciências sociais, apontam possíveis fontes de erros de mensuração.

Outra consequência de um questionário mal elaborado é permitir a manipulação das respostas segundo alguma pré-concepção inicial do pesquisador, o que produz falsos resultados para sua pesquisa. Este tipo de análise tendenciosa deve ser evitado a todo custo, pois camufla a realidade do objeto de estudo, tornando a pesquisa reprovável. Isto deve ser abolido: a despreocupação com o rigor da metodologia científica, e até mesmo, o seu desconhecimento

56 DOI: Em andamento.

R. Bras. de Ensino de C\&T 
pelo pesquisador. Este deve procurar ser imparcial para não contaminar o resultado da sua pesquisa.

Para evitar todos estes inconvenientes, é aconselhável a elaboração do questionário com a avaliação de uma pessoa experiente no assunto, sem deixar de seguir as etapas seguintes do préteste para a validação interna (GOODE e HATT, 1972).

Contudo, todas as sugestões propostas neste artigo devem ser interpretadas com a devida adequação para cada caso. Um exemplo é a necessidade de construção de um questionário longo, onde o pesquisador terá somente um único contato com o indivíduo pesquisado. Neste caso, o pesquisador deve fazer uma análise de custo-benefício, pois pode produzir um bom questionário mesmo que longo.

O processo de construção do questionário é contínuo e proporciona aprendizado através da experiência (CHAGAS, 2000). Mesmo depois de realizadas todas as etapas sugeridas aqui, se ao aplicar o questionário, o pesquisador perceber alguma pergunta mal formulada, esta deverá ser descartada das análises.

Destacamos ainda a necessidade do registro na construção do questionário. Um registro torna-se um documento da pesquisa, que mostra os passos trilhados pelo pesquisador no desenvolvimento do estudo. Um roteiro de questionário, como sugerido neste artigo, pode se tornar um registro completo, assim como um organizador mental, se abarcar todas as informações concernentes ao projeto de pesquisa realizado.

Justificamos, mais uma vez, a necessidade de escrever sobre o assunto, uma vez que percebemos várias dificuldades para a construção de seus questionários, nos alunos de graduação e pós-graduação. Esperamos contribuir tanto com o pesquisador novato como com o experiente na realização e orientação de seus questionários de pesquisa, porém, não intencionamos, de modo algum, esgotar o assunto.

Em última análise, para construirmos um questionário de pesquisa é preciso primeiramente estabelecer o nosso objetivo, etapa dependente de pesquisa bibliográfica - alicerce de todo o trabalho. Depois, devemos elaborar perguntas a partir de uma hipótese, o que orientará a formulação das questões que farão parte do questionário. A discussão de todos estes procedimentos faz parte de uma fase mais ampla, a metodologia de pesquisa, que apesar de não a aprofundarmos neste artigo, esperamos ter contribuído com nossos apontamentos.

\section{Referências}

APPLE, M. W. Relações de classe e de gênero e modificações no processo de trabalho docente. Cadernos de Pesquisa, São Paulo, n. 60, pp. 3-14, 1987. 
CHAGAS, A. T. R. O questionário na pesquisa científica. Administração on line, São Paulo, v. 1, n. 1, p. $1-14,2000 . \quad$ Disponivel em: http://xa.yimg.com/kg/groups/22703089/875888180/name/artigo\%252Bquestion\%2525C3\%252 5A1rio.pdf Acesso em 10 abr 2013.

GIL, A. C. Métodos e técnicas de pesquisa social. 6a ed. São Paulo: Atlas, 2009.

GIROUX, H. A. Os professores como intelectuais: rumo a uma pedagogia crítica da aprendizagem. Porto Alegre: Artes Médicas, 1997.

GOODE, W. J. e HATT, P. K. Métodos em pesquisa social. 4ạ ed. São Paulo: Nacional, 1972. GÜNTER, H. Como elaborar um questionário. (Série: Planejamento de Pesquisa nas Ciências Sociais, № 1) Brasília, DF: UnB, Laboratório de Psicologia Ambiental, 2003. Disponível em: http://beco-do-bosque.net/XTextos/01Questionario.pdf Acesso em 29 jun 2013.

GÜNTER, H. Pesquisa qualitativa versus pesquisa quantitativa: esta é a questão? Psicologia: Teoria e Pesquisa. v. 22, n. 2, pp. 201-210, 2006 . Disponível em: http://www.scielo.br/pdf/ptp/v22n2/a10v22n2.pdf Acesso em 10 jun 2014.

GURIDI, V.; VALADARES, J. M.; FERREIRA, D. B. e VILLANI, A. Introdução à Pesquisa em Ensino de Ciências: uma disciplina de pós-graduação visando a Formação de Pesquisadores. In: $V$ Encontro de Pesquisa em Educação em Ciências, Bauru SP, 2005. ATAS V ENPEC CD-ROM. Bauru -SP : ABRAPEC. $\quad$ v. único. $\quad$ p. 1-12. Disponível em: http://www.nutes.ufri.br/abrapec/venpec/conteudo/artigos/3/pdf/p577.pdf Acesso em 19 abr 2014.

HOSS, M. e CATEN, C. S. Processo de Validação Interna de um Questionário em uma Survey Research Sobre ISO 9001:2000. Produto \& Produção, v. 11, n. 2, pp. 104-119, 2010.

LUDKE, M. e ANDRÉ, M. E. D. A. Pesquisa em Educação: abordagens qualitativas. São Paulo: EPU, 1986.

MATTAR, F. N. Pesquisa de marketing: metodologia, planejamento, execução e análise. 2a ed., v. 2, São Paulo: Atlas, 1994.

MOREIRA, M. A. O professor-pesquisador como instrumento de melhoria do ensino de Ciências. Em Aberto, Brasília, ano7, n. 40, p. 43-54, 1988. Disponível em: http://www.emaberto.inep.gov.br/index.php/emaberto/article/viewFile/671/598 Acesso em 11 jun 2014.

NEVES, J. L. Pesquisa qualitativa - características, usos e possibilidades. Caderno de Pesquisas em Administração, São Paulo.v. 1, n.3, pp.1-5, 1996. Disponível em: http://www.dcoms.unisc.br/portal/upload/com arquivo/pesquisa qualitativa caracteristicas us os e possibilidades.pdf Acesso em 11 jun 2014.

58 DOI: Em andamento. R. Bras. de Ensino de C\&T 
PARASURAMAN, A. Marketing research, 2a ed. New York: Addison-Wesley Publishing Company, 1991.

ROSA, S. S. O sentido da pesquisa na formação inicial de professores: políticas e práticas do curso de pedagogia. Est. Aval. Educ., São Paulo, v. 21, n. 47, pp. 591-610, 2010. Disponível em: http://www.fcc.org.br/pesquisa/publicacoes/eae/arquivos/1610/1610.pdf Acesso em 11 jun 2014.

SANTOS, B. S. Um discurso sobre as ciências. 16a ed. Porto: Ed. Afrontamento, 2010.

SELLTIZ, C., WRIGHTSMAN, L. S. e COOK, S. W. Métodos de pesquisa nas relações sociais. 3a ed. São Paulo: EPU, 1987.

TURATO, E. R. Métodos qualitativos e quantitativos na área da saúde: definições, diferenças e seus objetos de pesquisa. Revista de Saúde Pública. v. 39, n.3, pp.507-514 , 2005. Disponível em: http://www.scielo.br/pdf/rsp/v39n3/24808.pdf Acesso em 11 jun 2014.

Waisenhowerk Vieira de Melo. Doutorando do Programa de Pós-graduação em Biologia das Interações (UFF); Professor assistente e coordenador do curso de Pós-graduação em Ensino de Ciências do Departamento de Ensino de Ciências e Biologia do Instituto de Biologia Roberto Alcântara Gomes. Universidade do Estado do rio de Janeiro - UERJ. werk@uerj.br

Cristina dos Santos Bianchi. Mestra em Biologia pela Universidade do Estado do Rio de Janeiro e Professora de Biologia da Rede Estadual de Ensino do Rio de Janeiro. Secretaria de Estado de Educação do Rio de Janeiro - SEEDUC/RJ. crisbianchibr@yahoo.com.br

DOI: Em andamento. 